DOI:10.2151/jmsj.87.513

\title{
Changes in Daily and Monthly Surface Air Temperature Variability by Multi-Model Global Warming Experiments
}

\author{
Akio KITOH \\ Meteorological Research Institute, Tsukuba, Japan \\ and \\ Tomohiko MUKANO ${ }^{1}$ \\ University of Tsukuba, Tsukuba, Japan \\ (Manuscript received 30 September 2008, in final form 8 December 2008)
}

\begin{abstract}
Future changes in daily and monthly surface air temperature variability are associated with temperature extremes and thus will have a large impact on our life and various sectors. In this study, we analyze variability of surface air temperature by 14 CMIP3 coupled ocean-atmosphere general circulation model results. We first assess the 20th century climate in coupled models $(20 \mathrm{C} 3 \mathrm{M})$ experiment for the period 1981-2000 with three reanalysis datasets and then show the changes in future climate for the period 2081-2100 under the SRES A1B scenario. The interannual variability of simulated monthly mean surface air temperature agrees with the observations based on three reanalysis datasets. Although there are large model-to-model scatters in the future changes of interannual variability, the ensemble mean of the available model results shows a large decrease in variability over the Northern Hemisphere high latitude region in winter, and an increase over the Northern Hemisphere midlatitudes and over the tropical land region in summer. For the daily temperature variability, the model ensemble mean underestimates the reanalysis data, probably related with less developed synoptic disturbances in the models than in reality. In future, the daily temperature variability is projected to increase over land in the Northern Hemisphere summer and in the tropics, and to decrease over the ocean throughout the year, consistent with the projected weakening of cyclonic disturbances. Inter-model variability is smaller than in the case for the interannual variability of monthly mean temperature.
\end{abstract}

\section{Introduction}

Future changes in anthropogenic forcing will result in not only the mean climate state but also the variability of climate (IPCC 2007). The changes in the variability will have larger impact on society than the changes in the mean of the climate, be-

Corresponding author: Akio Kitoh, Climate Research Department, Meteorological Research Institute, 1-1 Nagamine, Tsukuba, Ibaraki, 305-0052 Japan.

E-mail: kitoh@mri-jma.go.jp

1. Present affiliation: NS Solutions Corporation, Tokyo, Japan.

(C) 2009, Meteorological Society of Japan cause of difficulty of society's adaptation to change in extreme weather events. Therefore, information of precise projection of the variability is important as in the mean climate.

On the interannual variability of annual mean surface air temperature of 16 AOGCMs in the first stage of Coupled Modeling Intercomparison Project (CMIP1), Bell et al. (2000) find that majority of models have excessive temperature variability over land while simulated temperature variability over the ocean is generally too low. They find that models with a simple "bucket" type land surface scheme produce greater temperature variability over land due to lower levels of soil moisture than 
more realistic land surface schemes. Räisänen (2002) also finds an overestimation of temperature variability on low-latitude land areas with 19 CMIP2 models.

For future changes in surface air temperature variability, using the interannual variability in monthly mean surface air temperature of 19 AOGCMs in CMIP2, Räisänen (2002) finds a decrease in monthly mean surface air temperature variability during the cold season in the extratropical Northern Hemisphere and a slight increase of temperature variability at low latitudes and at warm season northern mid latitudes. The former is likely due to a decrease of sea ice and snow with increasing temperature. The summertime decreasing soil moisture in mid-latitude land surface contributes to the latter. Similar conclusions are drawn by Giorgi and Bi (2005) by the 18 AOGCMs under the SRES A2 scenario.

There are very few studies on the daily temperature variability. Based on a single model result in $\mathrm{CO}_{2}$-doubling experiments, Cao et al. (1992) find little change of daily standard deviations of surface temperature. Since then, many models data including daily model output have been made available under the third phase of CMIP (CMIP3). Therefore it is time to evaluate daily as well as monthly surface air temperature variability and their future changes by multi-model ensemble technique.

In this paper, we evaluate daily and monthly surface air temperature variability (standard deviation) using the 14 AOGCMs performed under the CMIP3 protocol. In Section 2, data and method are shown. Section 3 investigates interannual variability of monthly mean surface air temperature; first its evaluation of the present-day simulation against three reanalysis dataset, and then future projected changes of temperature variability are discussed. Daily surface air temperature variability in the present-day simulation and their future changes are shown in Section 4. Finally, discussion and conclusion are shown in Section 5.

\section{Data and method}

We use daily surface air temperature data for 20 years at the present day (1981-2000) of the 20C3M simulation and at the end of the twenty-first century (2081-2100) under the SRES A1B scenario simulation under the WCRP CMIP3 dataset. The 20C3M experiment has been simulated with natural (e.g., volcanoes and solar) and anthropogenic (e.g., greenhouse gases, ozone and aerosols) forcing in the 20th century. The SRES A1B experiment has been calculated with projected external forcing by the SRES A1B scenario from the end of the 20C3M simulation to 2100. The SRES A1B scenario represents a very rapid economic growth with increasing globalization into the future, and projects a $\mathrm{CO}_{2}$ concentration of 720 ppmv by the year 2100. Data of the following 14 models are used, for which 20 years daily data for the present as well as for the future were available at the time of analysis, i.e., CGCM3.1(T47), CGCM3.1(T63), CNRM-CM3, CSIRO-Mk3.0, ECHO-G, GFDLCM2.0, GISS-AOM， GISS-ER， INGV-SXG, INM-CM3.0, IPSL-CM4, MIROC3.2(hires), MIROC3.2(medres) and MRI-CGCM2.3.2. Details on each model are available from http:// www-pcmdi.llnl.gov/ipcc/about_ipcc.php. Only one member (the first member) is used even if multimember data are available for some models to equally treat each model. For evaluation purpose, we use three reanalysis datasets ERA-40 (Uppala et al. 2005), JRA-25 (Onogi et al. 2007) and NCEP/NCAR (Kalnay et al. 1996).

Interannual variability is defined as a standard deviation of monthly mean surface air temperature of each model for 20 years during 1981-2000 of the 20C3M experiment and during 2081-2100 of the SRES A1B scenario experiment. We do not remove linear trend during the 20 -year period as we in our life experience temperature variability with any trend added. Horizontal resolution varies from model to model with a range from about 1.125 degrees $\times$ 1.125 degrees to 4 degrees $\times 5$ degrees. Interannual variability is calculated at the original resolution of each model. They are interpolated into a common 2.5 degrees $\times 2.5$ degrees resolution, which is used to make a model ensemble mean. Reanalysis data are available in 2.5 degrees $\times 2.5$ degrees for ERA$40,1.25$ degrees $\times 1.25$ degrees for JRA-25, and 1.875 degrees $\times 1.875$ degrees for NCEP/NCAR.

Daily variability may be assessed in two ways. One way is similar to that of Cao et al. (1992) and to calculate standard deviations of daily mean surface air temperatures within each month of the year, and then make a long-term (say 20 years) mean for that month. In this way, however, an effect of a component of seasonal change may remain in calculated standard deviation particularly in transitional season between winter and summer in midand high-latitude regions. The other way is to first define a seasonal change by a 31-day cutoff lowpass filter, and to remove this component from the 
original daily values, and then calculate standard deviations of daily mean surface air temperatures within each month, and finally make a long-term (say 20 years) mean for that month. We did these two ways; the results are qualitatively similar to each other, but the former method results in about 30\% larger values than the latter method in the presentday annual mean surface air temperature variability over land. The change ratio is found to be similar between the two methods. In this paper, we present the results obtained by the latter method.

There is different treatment of the annual number of days among models. Four models (CNRM-CM3, GISS-AOM, MIROC3.2(hires) and MIROC3.2 (medres)) treat leap years explicitly, while seven models (CGCM3.1(T47), CGCM3.1(T63), CSIROMk3.0, GFDL-CM2.0, GISS-ER, INM-CM3.0, and MRI-CGCM2.3.2) use a 365-day calendar each year by ignoring leap years. Remaining three models (ECHO-G, INGV-SXG and IPSL-CM4)

(a) Land

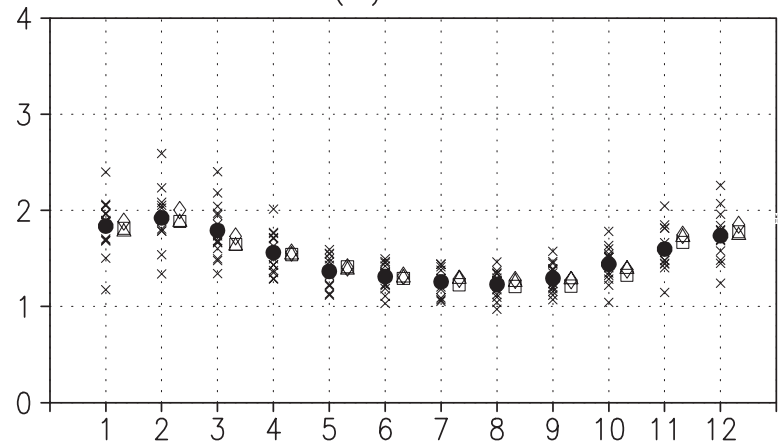

(b) Ocean

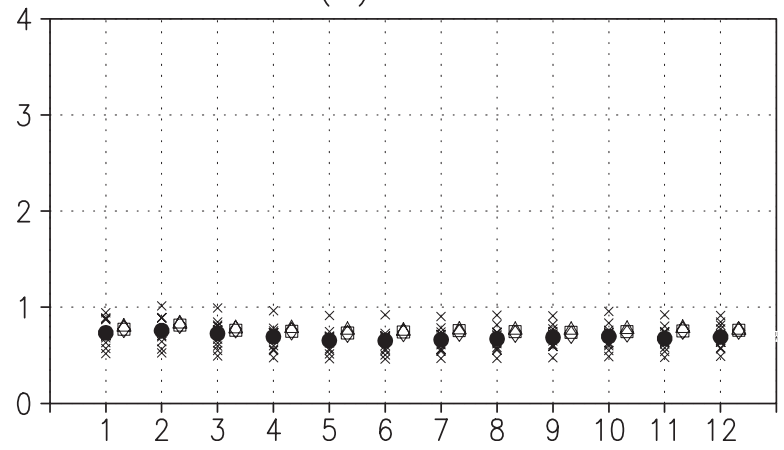

Fig. 1. Interannual variability of monthly mean surface air temperature $\left({ }^{\circ} \mathrm{C}\right)$ for each month for the present-day simulation averaged for (a) land and (b) ocean. $\times$ : each model. ๑: model ensemble mean, $\diamond$ : ERA-40, $\square$ : JRA-25, $\triangle$ : NCEP/NCAR. use a 360 days per year calendar. A 31-day cutoff low-pass filter was applied to each original model's calendar data, and then monthly mean data are calculated. For 360-day calendar models, each month is assumed 30 days. We assume that this different treatment of calendars may not cause significant qualitative differences in the results.

\section{Interannual variability of monthly mean surface air temperature}

\section{a. Monthly mean temperature variability in the control simulation}

Figure 1 shows the global mean interannual variability of monthly mean surface air temperature for each model, model ensemble mean and three reanalyses over land and ocean, respectively. Interannual variability of monthly mean surface air temperature over land is large during boreal winter and small during boreal summer, reflecting a larger portion of the Northern Hemisphere land area compared to that in the Southern Hemisphere. Over the ocean, the variability does not vary with season, and its value is smaller than that over land. There is a large scatter among the models. The range between the minimum and the maximum is

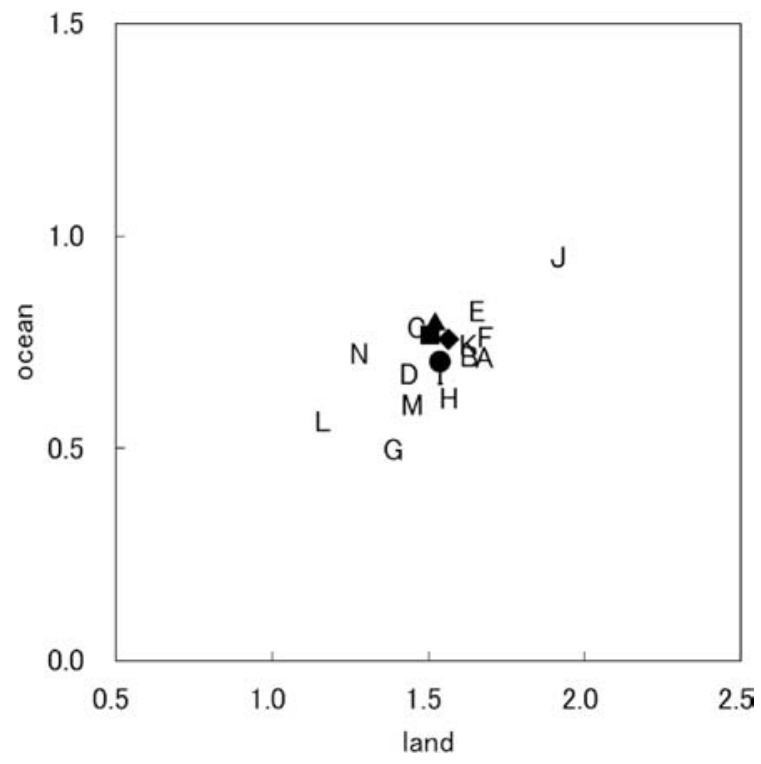

Fig. 2. Scatter diagram of annually and geographically averaged interannual variability of monthly mean surface air temperature $\left({ }^{\circ} \mathrm{C}\right)$ for the present-day simulation. A-N: each model. O: model ensemble mean, $\diamond:$ ERA-40, $\mathbf{\square}:$ JRA-25, $\mathbf{\Delta}$ : NCEP/ NCAR 
about twofold, and its range is larger in boreal winter. The model ensemble mean is defined as a simple average of all models. The model ensemble mean and the three reanalyses are in close agreement throughout a year.

Figure 2 shows the scatter diagram of annual mean values of monthly mean surface air temperature variability over land and ocean for each model, model ensemble mean and three reanalysis. Results are summarized in Table 1. The model value over land ranges almost twofold between 1.16 (MIROC3.2(hires)) and 1.91 (INM-CM3.0). The model ensemble mean is 1.53 , and is within a range of observed uncertainty where ERA-40, JRA-25 and NCEP/NCAR show 1.56, 1.50 and 1.52 , respectively. The model value over the ocean is smaller than that over land, but also ranges almost twofold between 0.48 (GISS-AOM) and 0.94 (INM-CM3.0). Contrary to that over land, the model ensemble mean $(0.69)$ is smaller than the reanalysis data, which is 0.75 (ERA), 0.76 (JRA) and 0.78 (NCEP/NCAR). This underestimation of interannual surface air temperature variability over the ocean may be associated with a still improper representation of El Niño/Southern Oscillation (ENSO) and/or decadal variability in the models. Although AchutaRao and Sperber (2006) show that the CMIP3 models better reproduce the El Niño amplitude compared to the CMIP2 models, there still remains a problem of too narrow ENSO phenomena in the models. It is noticeable that the model with large temperature variability over the ocean also has large temperature variability over land.

The control experiments (20C3M) of 14 CMIP3 models show large interannual variability of monthly mean surface air temperature over the northern hemisphere mid- and high-latitude land areas in winter. Earlier studies (e.g., Bell et al. 2000, Räisänen 2002) suggest an overestimation of simulated variability against the observation, but this study shows that the interannual variability of simulated monthly mean surface air temperature agrees well with the observations based on three reanalysis datasets. Bell et al. (2000) show that models with sophisticated physical process in the whole have better skill in their interannual variability. Recent model development such as in land surface

Table 1. Annually and geographically averaged interannual standard deviation of monthly mean surface air temperature for present, future, their difference and change ratio.

\begin{tabular}{|c|c|c|c|c|c|c|c|c|c|}
\hline & & \multicolumn{4}{|c|}{ land } & \multicolumn{4}{|c|}{ ocean } \\
\hline & & $20 \mathrm{C} 3 \mathrm{M}$ & SRES A1B & difference & change ratio & $20 \mathrm{C} 3 \mathrm{M}$ & SRES A1B & difference & change ratio \\
\hline & & $\mathrm{K}$ & $\mathrm{K}$ & $\mathrm{K}$ & $\%$ & $\mathrm{~K}$ & $\mathrm{~K}$ & $\mathrm{~K}$ & $\%$ \\
\hline A & CGCM3.1(T47) & 1.67 & 1.65 & -0.02 & -1.18 & 0.70 & 0.65 & -0.05 & -7.20 \\
\hline B & CGCM3.1(T63) & 1.62 & 1.57 & -0.05 & -3.34 & 0.71 & 0.61 & -0.10 & -14.28 \\
\hline $\mathrm{C}$ & CNRM-CM3 & 1.46 & 1.46 & 0.00 & -0.12 & 0.77 & 0.74 & -0.03 & -3.74 \\
\hline $\mathrm{D}$ & CSIRO-MK3.0 & 1.43 & 1.43 & 0.00 & 0.00 & 0.66 & 0.61 & -0.05 & -8.25 \\
\hline $\mathrm{E}$ & ECHO-G & 1.65 & 1.53 & -0.12 & -7.03 & 0.81 & 0.68 & -0.14 & -16.65 \\
\hline $\mathrm{F}$ & GFDL-CM2.0 & 1.68 & 1.57 & -0.11 & -6.41 & 0.75 & 0.67 & -0.09 & -11.39 \\
\hline G & GISS-AOM & 1.38 & 1.38 & 0.01 & 0.44 & 0.48 & 0.48 & -0.01 & -1.58 \\
\hline $\mathrm{H}$ & GISS-ER & 1.56 & 1.55 & -0.01 & -0.47 & 0.61 & 0.57 & -0.04 & -5.74 \\
\hline I & INGV-SXG & 1.53 & 1.49 & -0.04 & -2.56 & 0.66 & 0.61 & -0.05 & -8.22 \\
\hline $\mathbf{J}$ & INM-CM3.0 & 1.91 & 1.75 & -0.16 & -8.47 & 0.94 & 0.80 & -0.14 & -15.06 \\
\hline K & IPSL-CM4 & 1.62 & 1.61 & -0.01 & -0.54 & 0.73 & 0.68 & -0.05 & -6.94 \\
\hline $\mathrm{L}$ & MIROC3.2(hires) & 1.16 & 1.36 & 0.19 & 16.60 & 0.55 & 0.58 & 0.03 & 5.71 \\
\hline M & MIROC3.2(medres) & 1.44 & 1.44 & -0.01 & -0.42 & 0.59 & 0.58 & 0.00 & -0.41 \\
\hline $\mathrm{N}$ & MRI-CGCM2.3.2 & 1.27 & 1.32 & 0.05 & 4.15 & 0.71 & 0.73 & 0.02 & 2.86 \\
\hline ○ & model mean & 1.53 & 1.51 & -0.02 & -1.26 & 0.69 & 0.64 & -0.05 & -7.19 \\
\hline & model s.d. & 0.19 & 0.12 & 0.08 & 6.00 & 0.11 & 0.08 & 0.05 & 6.64 \\
\hline & ERA & 1.56 & & & & 0.75 & & & \\
\hline & JRA & 1.50 & & & & 0.76 & & & \\
\hline $\boldsymbol{\Delta}$ & NCEP & 1.52 & & & & 0.78 & & & \\
\hline
\end{tabular}


processes may have contributed to more agreement with the observations. However, the inter-model scatter of interannual variability of monthly mean surface air temperature is still very large. This may be due to insufficient representation of various phenomena such as El Niño/Southern Oscillation and Northern Annular Mode in most models (IPCC 2007).

\section{b. Changes in monthly mean temperature variability}

Figure 3 shows the future change ratio in $\%$ from 1981-2000 (20C3M) to 2081-2100 (SRES A1B) of the global mean interannual variability of monthly mean surface air temperature for each model and model ensemble mean over land and the ocean, respectively. Based on the model ensemble mean, the variability of monthly mean surface air temperature over land is projected to decrease at the end of the 21st century between October and April with largest decrease in December $(-5.8 \% \pm 8.4 \%)$. It is projected to increase in boreal summer with the

(a) Land

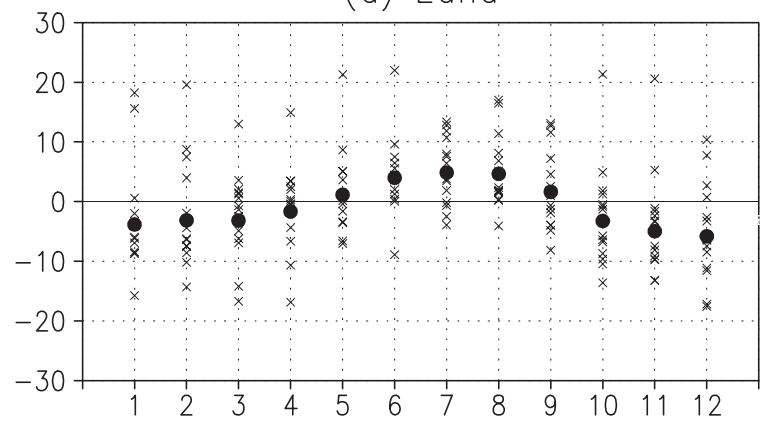

(b) Ocean

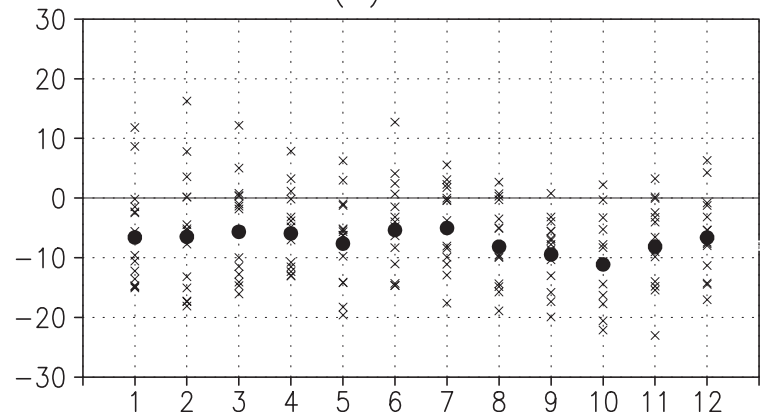

Fig. 3. Change ratio $(\%)$ of interannual variability of monthly mean surface air temperature for each month from the present to the future averaged for (a) land and (b) ocean. $\times$ : each model. $\bigcirc$ : model ensemble mean. largest increase in July $(+4.9 \% \pm 5.8 \%)$. However, inter-model difference is large throughout the year. One model shows an increase in temperature variability throughout the year, while other models show seasonal change of the sign as in the model ensemble mean. Over the ocean, the model ensemble mean shows a decrease in the monthly mean temperature variability throughout the year between $-5.0 \%$ (July) and $-11.1 \%$ (October). Again, inter-model variability is large ranging from a $23 \%$ decrease to a $16 \%$ increase in particular month. Out of 14 models, 7 models show a decrease in the monthly mean temperature variability throughout the year.

Figure 4 shows the scatter diagram of annual mean change ratio between 1981-2000 and 20812100 in the monthly mean surface air temperature variability over land and ocean for each model and the model ensemble mean. It is shown that ECHOG, INM-CM3.0, CGCM3.1(T63) and GFDLCM2.0 show a large decrease in monthly mean temperature variability both over land and over the ocean, while MIROC3.2(hires) and MRICGCM2.3.2 show an increase in variability. The model ensemble mean value is $-1.3 \%( \pm 6.0 \%)$ over land and $-7.2 \%( \pm 6.6 \%)$ over the ocean. As

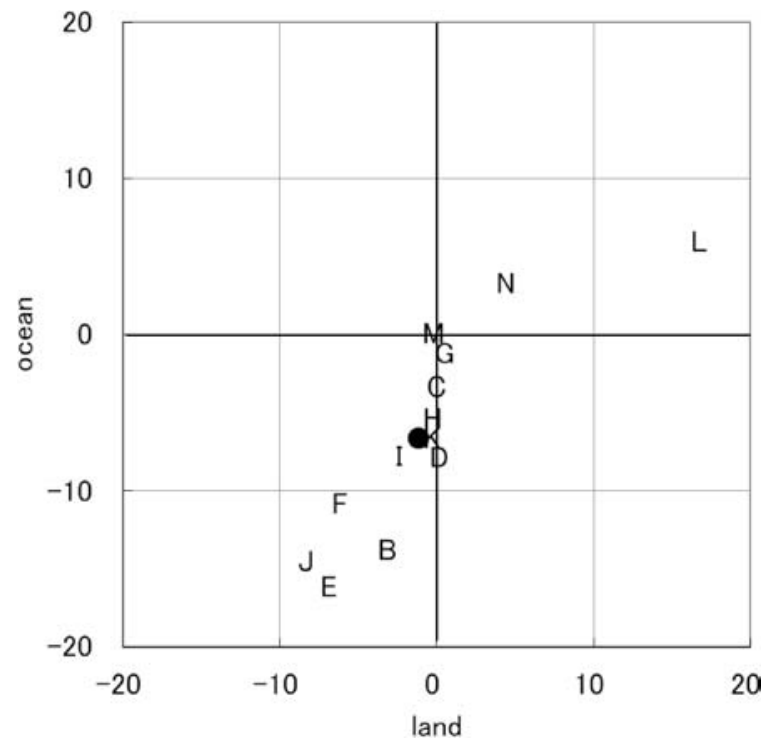

Fig. 4. Scatter diagram of change ratio (\%) of annually and geographically averaged interannual variability of monthly mean surface air temperature from the present to the future. A-N: each model. $\bigcirc$ : model ensemble mean. 
(a) DJF

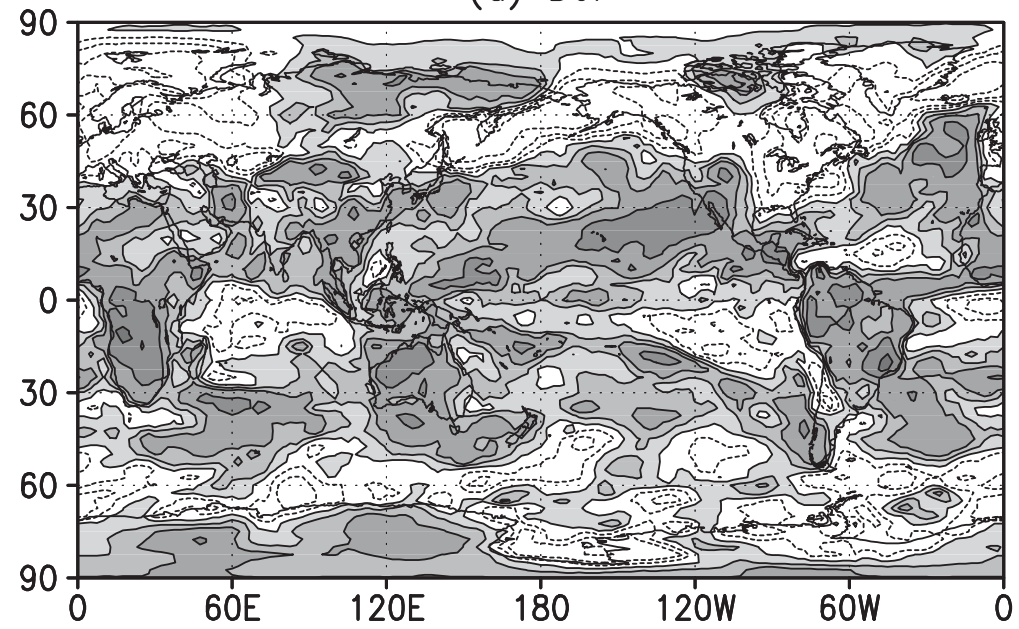

(b) JJA

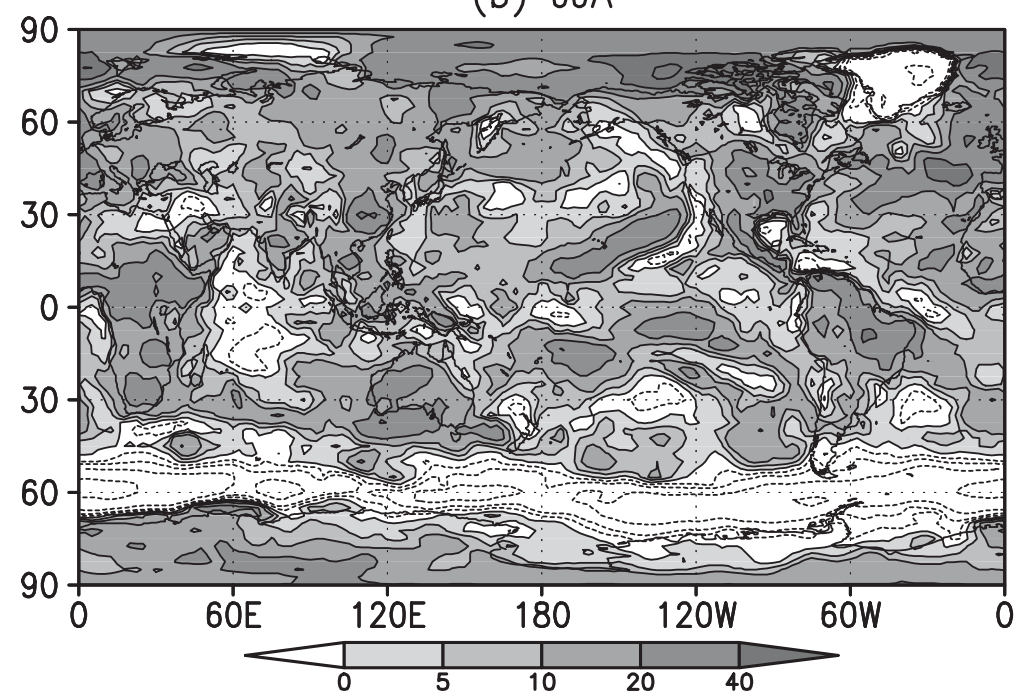

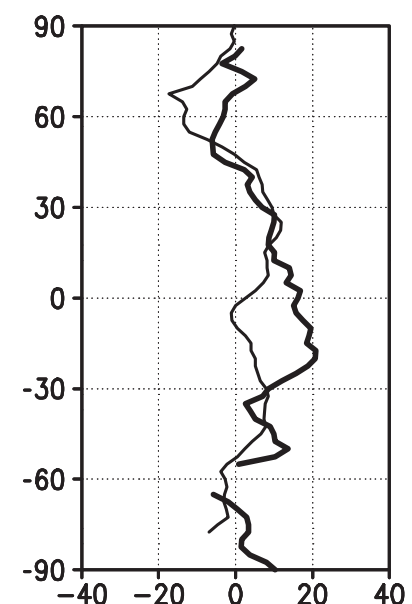

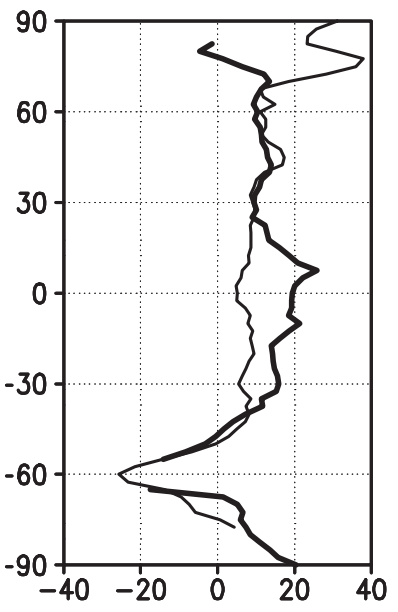

Fig. 5. Geographical distribution of change ratio (\%) from the present to the future of (a) DJF and (b) JJA averaged interannual variability of monthly mean surface air temperature. Line plots show the zonal average over land (thick) and over the ocean (thin).

shown in Fig. 3, a small annual mean change over land comes from seasonal compensation where it increases in boreal summer and decreases in boreal winter.

Figure 5 shows the December-February average and the June-August average of model ensemble mean change ratio between 1981-2000 and 20812100 in interannual variability of monthly mean surface air temperature. In the December-February season, a large decrease in temperature variability appears over the northern hemisphere continent north of $30^{\circ} \mathrm{N}$. This suggests a decreasing risk of severe winter in northern high latitude regions. There are regions with increased variability such as tropical land regions and some of the subtropical oceans. In June-August, a decrease is seen over the southern ocean, but an increased variability is projected over the continent worldwide. In particular, summertime variability is projected to increase over Europe, Americas and Asia, where a risk of hot summer and cold summer may increase in the future. 


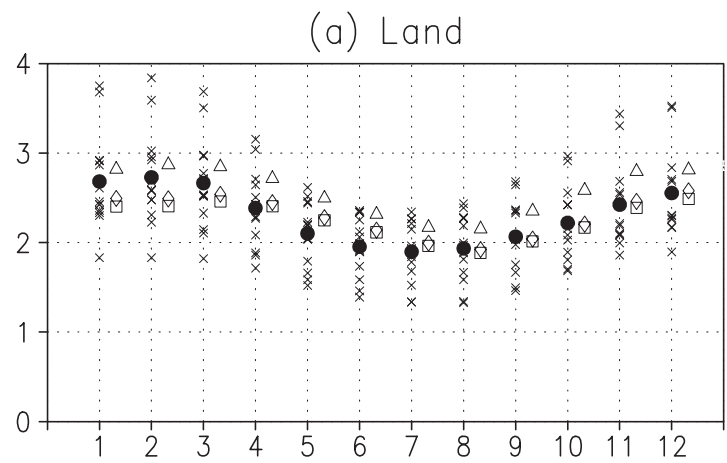

(b) Ocean

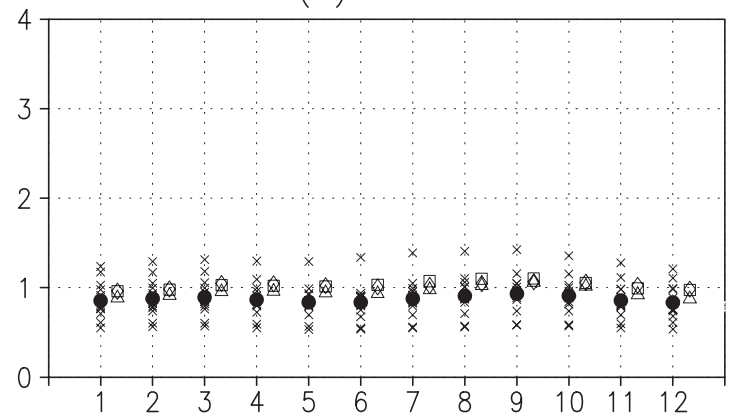

Fig. 6. Daily mean surface air temperature variability $\left({ }^{\circ} \mathrm{C}\right)$ for each month for the present-day simulation averaged for (a) land and (b) ocean. $\times$ : each model. $\mathbf{0}$ model ensemble mean, $\diamond$ : ERA-40, JRA-25, $\triangle$ : NCEP/NCAR.

\section{Interannual variability of daily surface air temperature}

a. Daily temperature variability in the control simulation

Figure 6 shows the global mean of daily surface air temperature variability for each model, model ensemble mean and three reanalysis data over land and ocean, respectively. General pattern is similar to that in the interannual variability of monthly mean surface air temperature, such that it is large in boreal winter and small in boreal summer over land, that over the ocean it is smaller than that over land and is almost constant throughout the year. This figure is drawn from the filtered daily data. The daily temperature variability without a filter results in about $20-30 \%$ larger values, but the characteristics are similar (not shown). Model-tomodel variability is again large in boreal winter land data. Over land, the model ensemble mean is smaller than the three reanalysis data in boreal

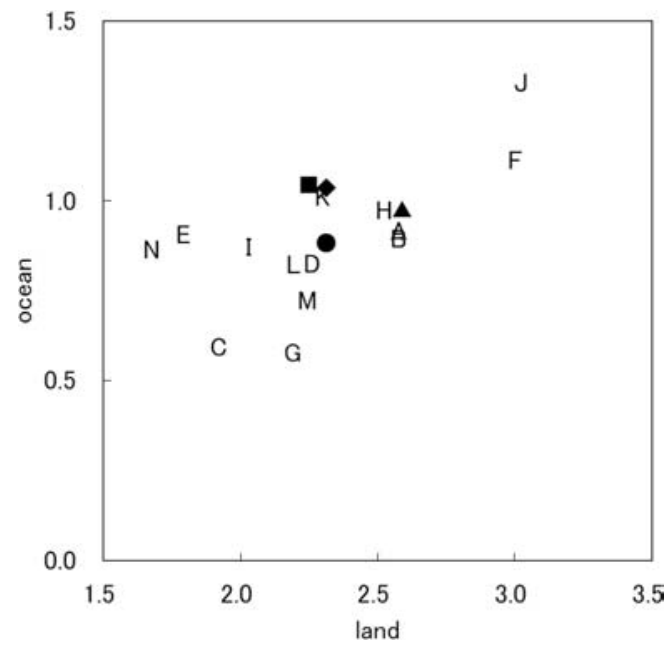

Fig. 7. Scatter diagram of annually and geographically averaged daily mean surface air temperature variability $\left({ }^{\circ} \mathrm{C}\right)$ for the present-day simulation. A-N: each model. ๑: model ensemble mean, $\bullet$ : ERA-40, JRA-25, $\mathbf{\Delta}:$ NCEP/NCAR.

summer, but both are comparable to each other in other seasons. Over the ocean, the model ensemble mean is smaller than the three reanalysis data throughout the year.

Figure 7 shows the scatter diagram of annual mean values of global mean daily surface air temperature variability over land and ocean for each model, model ensemble mean and three reanalysis data. Table 2 summarizes the results. The model value over land ranges between 1.66 (MRICGCM2.3.2) and 3.02 (INM-CM3.0). The model ensemble mean is 2.30 , and is within uncertainty of reanalysis data of 2.30 (ERA), 2.24 (JRA) and 2.58 (NCEP/NCAR). Among the three reanalysis data, NCEP/NCAR shows larger values than the other two reanalysis. The model value over the ocean is smaller than that over land, but ranges more than twice between 0.56 (GISS-AOM) and 1.32 (INMCM3.0). Contrary to that over land, the model ensemble mean (0.87) is smaller than the all reanalysis data, which is 1.02 (ERA), 1.03 (JRA) and 0.96 (NCEP/NCAR).

In summary, the inter-model scatter of daily surface air temperature variability is very large as in the case of the interannual variability of monthly mean temperature, and the model ensemble mean over land is in close agreement with the reanalysis 
Table 2. Annual and geographical average of daily surface air temperature variability for present, future, their difference and change ratio.

\begin{tabular}{|c|c|c|c|c|c|c|c|c|c|}
\hline & & \multicolumn{4}{|c|}{ land } & \multicolumn{4}{|c|}{ ocean } \\
\hline & & $20 \mathrm{C} 3 \mathrm{M}$ & SRES A1B & difference & change ratio & 20C3M & SRES A1B & difference & change ratio \\
\hline & & $\mathrm{K}$ & $\mathrm{K}$ & $\mathrm{K}$ & $\%$ & $\mathrm{~K}$ & $\mathrm{~K}$ & $\mathrm{~K}$ & $\%$ \\
\hline A & CGCM3.1(T47) & 2.57 & 2.54 & -0.03 & -1.33 & 0.88 & 0.82 & -0.06 & -6.78 \\
\hline B & CGCM3.1(T63) & 2.57 & 2.49 & -0.08 & -2.93 & 0.89 & 0.76 & -0.13 & -14.71 \\
\hline $\mathrm{C}$ & CNRM-CM3 & 1.91 & 1.90 & -0.01 & -0.47 & 0.58 & 0.54 & -0.04 & -6.81 \\
\hline $\mathrm{D}$ & CSIRO-MK 3.0 & 2.25 & 2.23 & -0.02 & -0.95 & 0.81 & 0.76 & -0.05 & -6.32 \\
\hline $\mathrm{E}$ & ECHO-G & 1.78 & 1.68 & -0.10 & -5.76 & 0.89 & 0.82 & -0.07 & -7.83 \\
\hline $\mathrm{F}$ & GFDL-CM2.0 & 3.00 & 2.86 & -0.14 & -4.75 & 1.10 & 0.97 & -0.13 & -11.97 \\
\hline G & GISS-AOM & 2.18 & 2.19 & 0.02 & 0.82 & 0.56 & 0.52 & -0.04 & -6.60 \\
\hline $\mathrm{H}$ & GISS-ER & 2.52 & 2.49 & 0.03 & 1.03 & 0.96 & 0.91 & 0.05 & 5.65 \\
\hline I & INGV-SXG & 2.02 & 1.90 & -0.12 & -5.95 & 0.86 & 0.75 & -0.11 & -13.09 \\
\hline $\mathbf{J}$ & INM-CM3.0 & 3.02 & 2.83 & -0.19 & -6.39 & 1.32 & 1.16 & -0.16 & -12.35 \\
\hline K & IPSL-CM4 & 2.29 & 2.21 & -0.08 & -3.38 & 1.00 & 0.89 & -0.11 & -11.29 \\
\hline $\mathrm{L}$ & MIROC3.2(hires) & 2.19 & 2.13 & -0.05 & -2.39 & 0.81 & 0.68 & -0.13 & -16.46 \\
\hline M & MIROC3.2(medres) & 2.24 & 2.16 & -0.08 & -3.73 & 0.71 & 0.65 & -0.07 & -9.34 \\
\hline $\mathrm{N}$ & MRI-CGCM2.3.2 & 1.66 & 1.64 & -0.02 & -0.99 & 0.85 & 0.78 & -0.07 & -8.45 \\
\hline \multirow[t]{2}{*}{ - } & model mean & 2.30 & 2.23 & -0.07 & -2.91 & 0.87 & 0.79 & -0.09 & -10.10 \\
\hline & model s.d. & 0.41 & 0.38 & 0.06 & 2.27 & 0.20 & 0.17 & 0.04 & 3.47 \\
\hline & ERA & 2.30 & & & & 1.02 & & & \\
\hline & JRA & 2.24 & & & & 1.03 & & & \\
\hline $\boldsymbol{\Delta}$ & NCEP & 2.58 & & & & 0.96 & & & \\
\hline
\end{tabular}

data but that over the ocean underestimates the reanalysis data. The daily surface air temperature variability may be associated with synoptic weather phenomena, and thus the CMIP3 models on the whole seem to have less developed synoptic disturbances over the ocean. The large difference of daily variability among the CMIP3 models should be associated with different synoptic disturbances and also land surface processes. Attributing different daily surface temperature variability among the models to these relationships would be an important subject to explore.

\section{b. Changes in daily temperature variability}

Figure 8 shows the future change ratio in $\%$ from 1981-2000 (20C3M) to 2081-2100 (SRES A1B) of the global mean daily surface air temperature variability for each model and model ensemble mean. Similar to the changes in interannual variability of monthly mean temperature, future daily temperature variability increases in boreal summer over land, and decreases in other seasons over land and throughout the year over the ocean. It is noticeable that inter-model variability of daily temperature variability is smaller than the case for the interannual variability of monthly mean temperature, and model-to-model consistency is high in JuneJuly and November-February over land. In January, one model is an outlier with an increased variability. In July, two models show a decreased variability while other 12 models show an increased variability. Over the ocean, all models show a decrease in daily temperature variability in every month.

Figure 9 shows the scatter diagram of annual mean change ratio between 1981-2000 and 20812100 in daily surface air temperature variability over land and ocean for each model and model ensemble mean. It ranges from $-6.4 \%$ (INM-CM3.0) to $+0.8 \%$ (GISS-AOM) over land, and $-16.5 \%$ (MIROC3.2(hires)) to $-5.6 \%$ (GISS-ER) over the ocean. Only the GISS-AOM shows an increase in daily temperature variability over land in its annual mean. All models project a decrease in daily temperature variability over the ocean. The model ensemble mean value of the change ratio is $-2.9 \%$ $( \pm 2.3 \%)$ over land and $-10.1 \%( \pm 3.5 \%)$ over the ocean. 


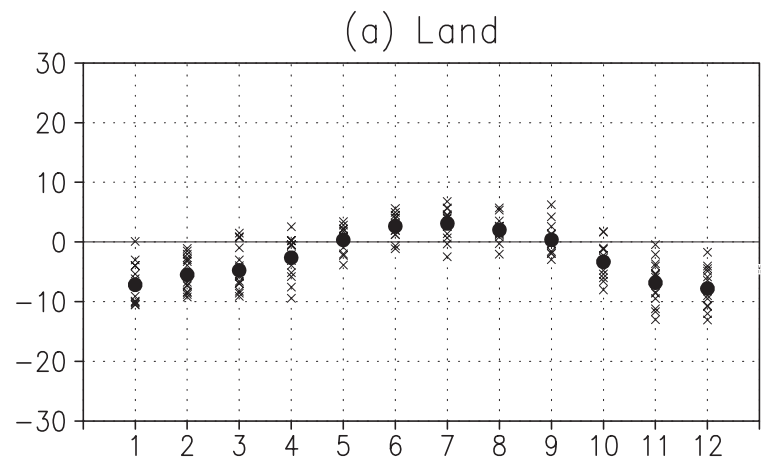

(b) Ocean

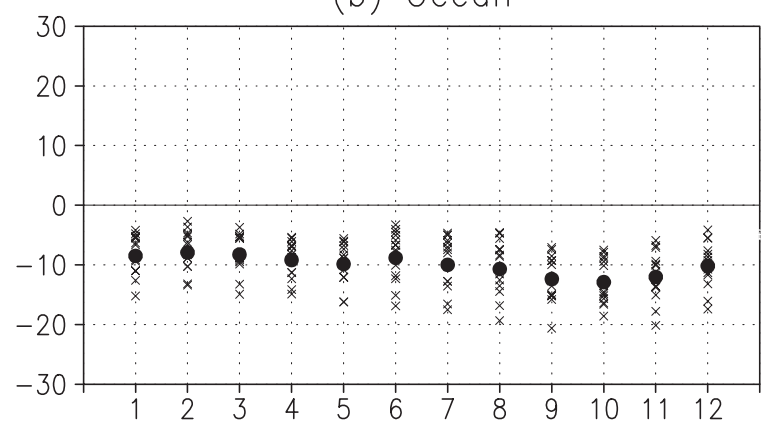

Fig. 8. Change ratio (\%) of daily mean surface air temperature variability for each month from the present to the future averaged for (a) land and (b) ocean. $\times$ : each model. $\bullet$ : model ensemble mean.

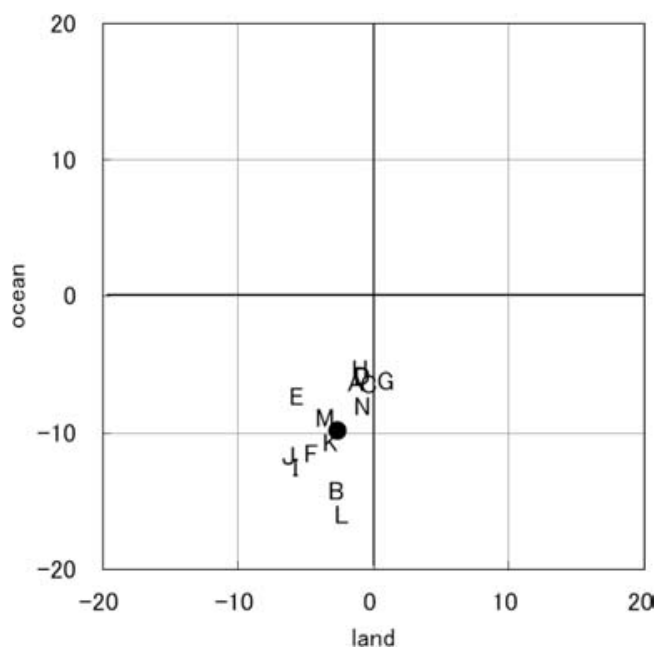

Fig. 9. Scatter diagram of change ratio (\%) of annually and geographically averaged daily mean surface air temperature variability from the present to the future. A$\mathrm{N}$ : each model. 0 : model ensemble mean.
Figure 10 shows the geographical distributions of the December-February average and the JuneAugust average of model ensemble mean change ratio between 1981-2000 and 2081-2100 in daily surface air temperature variability. In the December-February season, a large decrease (more than $20 \%$ ) in daily temperature variability appears over the northern hemisphere high latitude regions. It increases over tropical land and southern hemisphere continent regions. In June-August, northern hemisphere mid- and high-latitude land areas experience increased daily temperature variability together with tropical land and southern hemisphere continent regions. Those areas with increasing variability are found over Europe, Sahel, India, Thailand, Mexico and northern South America. An increasing temperature in the future climate will result in higher evaporation. The CMIP3 models project that soil moisture content decreases in the subtropics and the Mediterranean region as well as at high latitudes (IPCC 2007). As in the case for the increasing interannual variability of monthly mean surface air temperature over summertime continent, drier land in the projected future climate should be associated with increasing daily temperature variability.

Over the oceans, there is an overall decrease in both seasons in daily temperature variability with the largest decreases over the Arctic Ocean and the southern circum-Antarctic oceans. This is in contrast with the case for the interannual variability of monthly mean surface air temperature where there is no systematic changes in variability (Fig. 5).

\section{Discussion and conclusions}

In this study, we analyzed variability of surface air temperature by 14 coupled ocean-atmosphere general circulation models under the CMIP3 multimodel dataset. We utilized the 20 th century climate in coupled models $(20 \mathrm{C} 3 \mathrm{M})$ experiment for the period 1981-2000 and the future climate simulation for the period 2081-2100 under the SRES A1B scenario. The ensemble mean of interannual variability of simulated monthly mean surface air temperatures agreed well with the observations based on the three reanalysis datasets. There are large modelto-model scatter in the future changes of interannual variability. However, ensemble mean of available model results shows a large decrease in variability over the Northern Hemisphere highlatitude region in winter, and an increase over the Northern Hemisphere mid-latitudes and over the tropical land region in summer. These results are 
(a) DJF
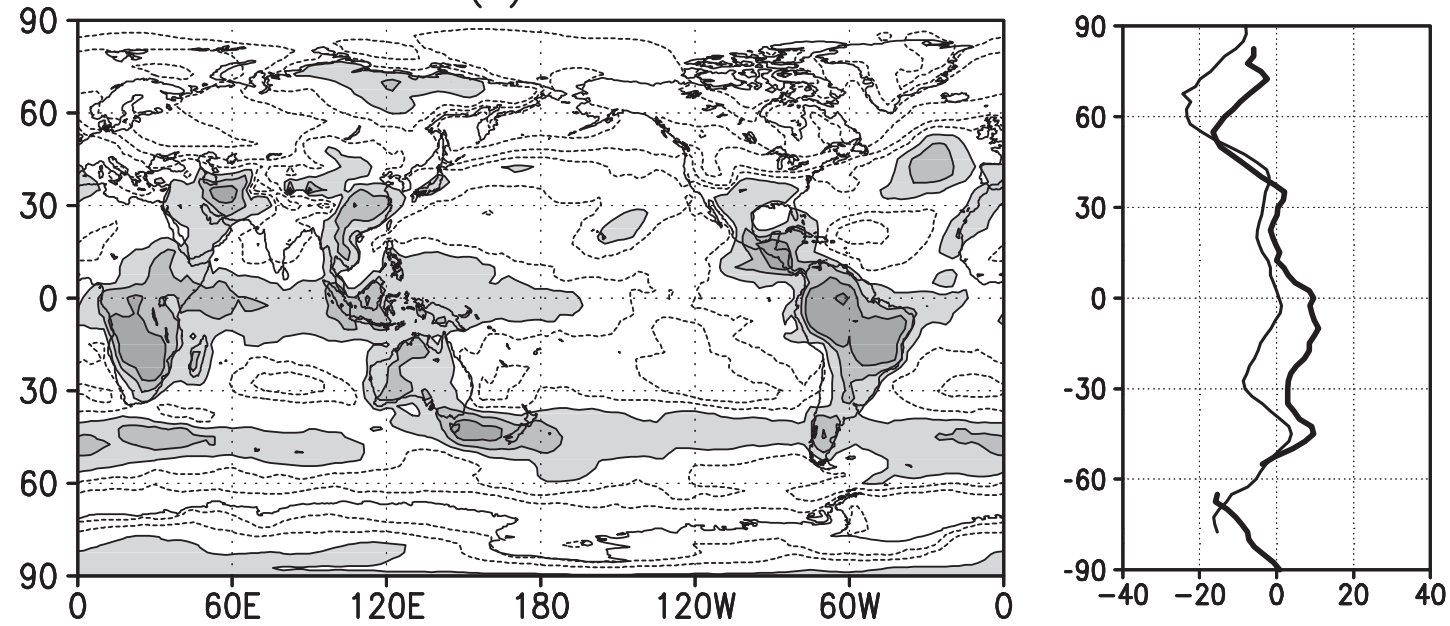

(b) JJA
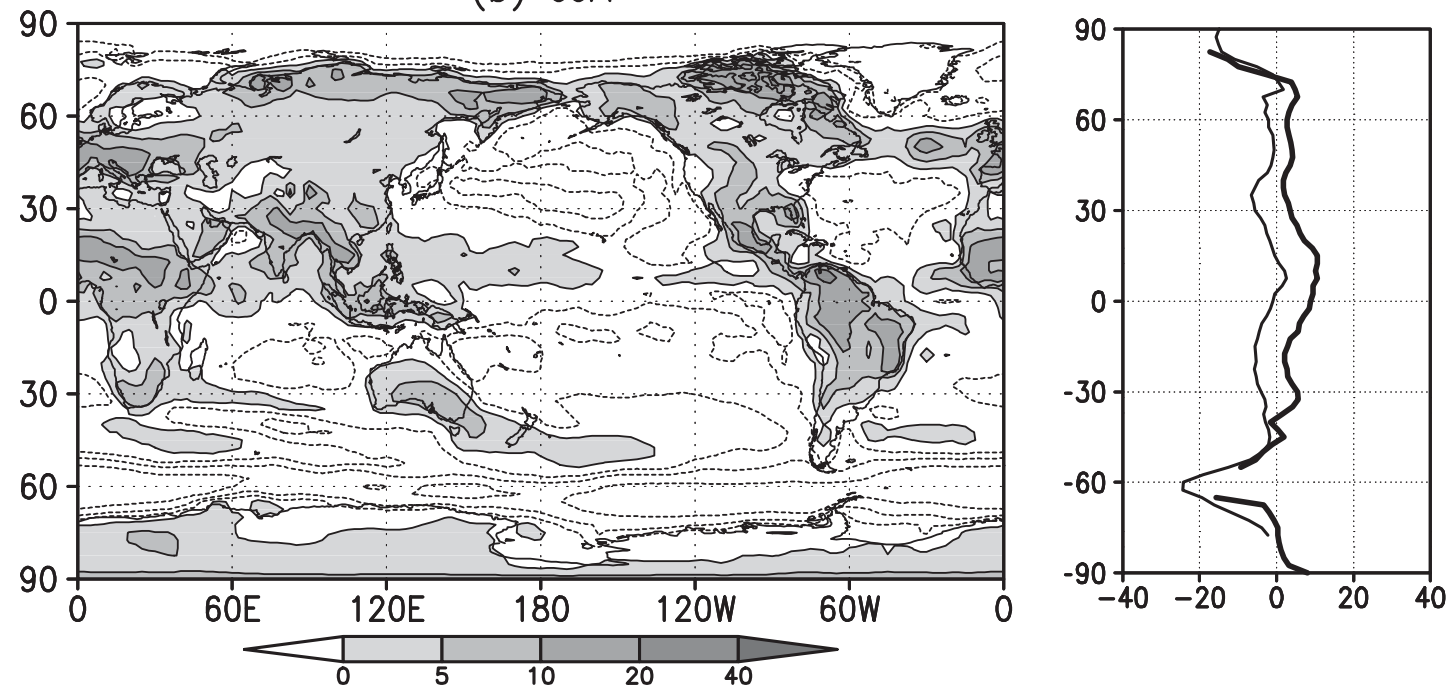

Fig. 10. Geographical distribution of change ratio (\%) from the present to the future of (a) DJF and (b) JJA averaged daily mean surface air temperature variability. Line plots show the zonal average over land (thick) and over the ocean (thin).

in accordance with the earlier studies based on CMIP1 and CMIP2 AOGCMs.

We did not remove the linear trend during the analyzed 20-year period because the interannual temperature variability with any trend is what we feel in our real life. This method is different from that of Räisänen (2002). Judging from global mean surface air temperature changes from the AR4 models with the SRES A1B scenario (IPCC 2007), one may anticipate a larger linear trend in monthly mean temperature in the 21st century compared with that in the 20th century. Thus the results on interannual variation in this paper are overestimated compared with detrended results.

For daily temperature variability, it is projected to decrease over the high-latitude oceans, and to increase over land in the Northern Hemisphere summer and in the tropics. The former is consistent with a projected decrease in the number of midlatitude cyclone events in winter (Lambert and Fyfe 2006). Inter-model variability is smaller than the case for the interannual variability of monthly mean temperature.

It is also noted that models with large inter- 
annual variability of monthly mean temperature show large daily temperature variability both for the present and for the future, and also both over land and over the ocean. However, the annual mean values of the change ratio of the interannual variability of monthly mean temperature from the present to the future in the 14 models are statistically correlated with the annual mean values of the change ratio of the daily temperature variability only over land. Inter-model correlation coefficient is 0.485 over land and 0.033 over the ocean. Importance of land surface model on daily to monthly mean temperature variability is thus largely suggested. This elaboration is beyond the scope of the present paper, but should be investigated in continuing work.

In this paper, we did not weigh each model result based on its skill in reproducing temperature variability at the present climate, as a skill can be defined in various ways. Here we just show one example. A model skill in reproducing daily surface air temperature variability in the present climate is defined in each month as a distance of global mean daily surface air temperature variability from an ensemble mean of that value in the reanalysis data. The value is then adjusted between 0 and 1. Finally an annual mean value is calculated. The skill thus obtained is: $0.910,0.879,0.116$, (a) DJF w

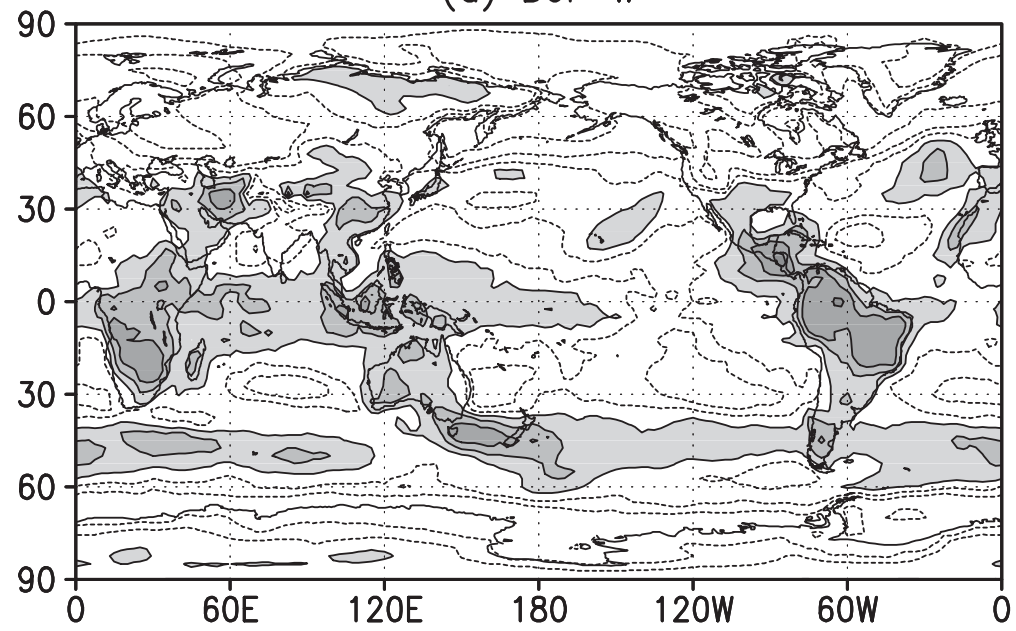

(b) JJA w

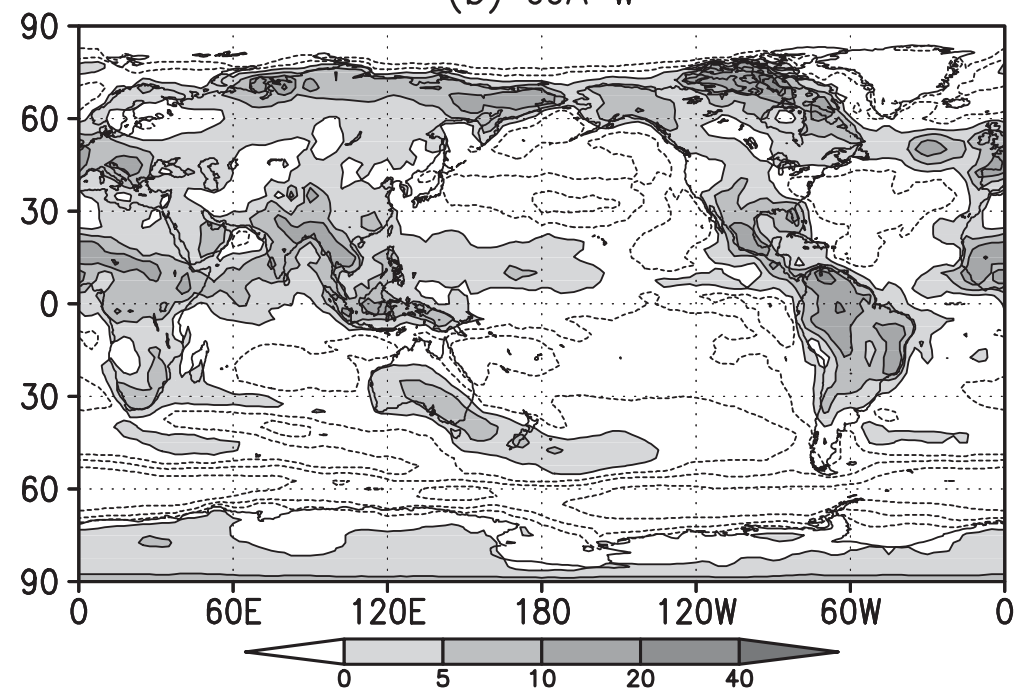

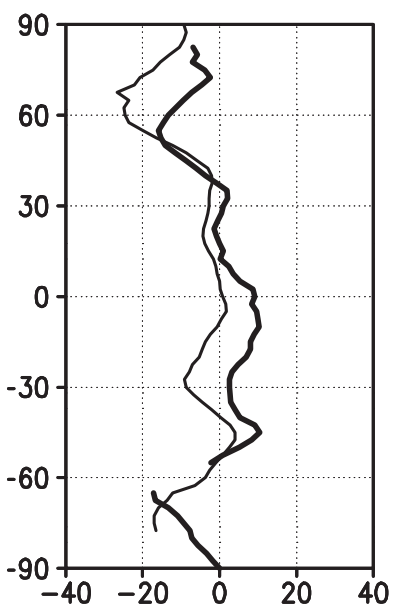

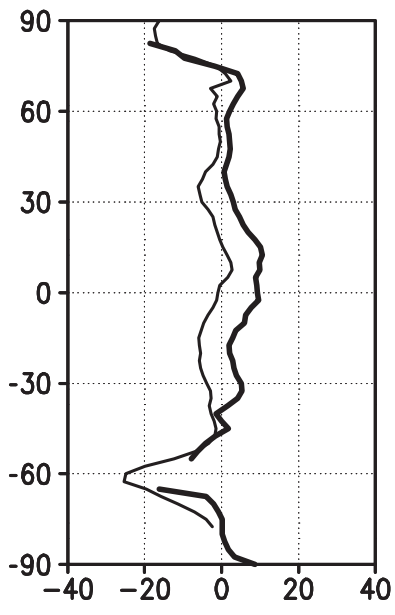

Fig. 11. As in Fig. 10 except for skill-weighted daily mean surface air temperature variability. 


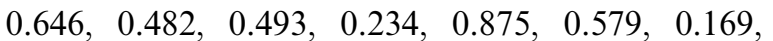
$0.853,0.608,0.499$ and 0.354 for model A-N, respectively. Figure 11 shows the geographical distributions of the December-February average and the June-August average of skill-weighted model ensemble mean change ratio between 1981-2000 and 2081-2100 in daily surface air temperature variability. The difference between Fig. 10 and Fig. 11 is so small, indicating that a simple ensemble averaging technique is a good way in our case. The models with large temperature variability tend to show large changes in the future climate projections, and vice versa. This is one of the reasons why a simple ensemble average and a skill-weighted average are not so different.

Our results show that the change in monthly mean temperature variability in the future climate is only one aspect and daily temperature variability will also change largely. The present results that increasing daily temperature variability in the future warming climate over land in the Northern Hemisphere in summer and in the tropics imply more extreme hot days in summer. Still there are large differences in each model's skill in reproducing present-day temperature variability, which should be associated with various meteorological phenomena, and imply room for improving the models.

\section{Acknowledgments}

This work is supported by the Global Environmental Research Fund (S-5-2). We acknowledge the international modeling groups for providing their data for analysis, the Program for Climate Model Diagnosis and Intercomparison (PCMDI) for collecting and archiving the model data, the JSC/CLIVAR Working Group on Coupled Modelling (WGCM) and their Coupled Model Intercomparison Project (CMIP) and Climate Simulation Panel for organizing the model data analysis activity, and the IPCC WG1 TSU for technical support.
The IPCC Data Archive at Lawrence Livermore National Laboratory is supported by the Office of Science, U.S. Department of Energy.

\section{References}

AchutaRao, K., and K. R. Sperber, 2006: ENSO simulation in coupled ocean-atmosphere models: are the current models better? Clim. Dyn., 27, 1-15.

Bell, J., P. Duffy, C. Covey, L. Sloan, and the CMIP investigators, 2000: Comparison of temperature variability in observations and sixteen climate model simulations. Geophys. Res. Lett., 27, 261-264.

Cao, H. X., J. F. B. Mitchell, and J. R. Lavery, 1992: Simulated diurnal range and variability of surface temperature in a global climate model for present and doubled $\mathrm{CO}_{2}$ climates. J. Climate, 5, 920-943.

Giorgi, F., and X. Bi, 2005: Regional changes in surface climate interannual variability for the 21 st century from ensembles of global model simulations. Geophys. Res. Lett., 32, L13701, doi:10.1029/ 2005GL023002.

IPCC, 2007: Climate Change 2007: The Physical Science Basis. Contribution of Working Group I to the Fourth Assessment Report of the Intergovernmental Panel on Climate Change. S. Solomon, D. Qin, M. Manning, Z. Chen, M. Marquis, K. B. Averyt, M. Tignor, and H. L. Miller (Eds.), Cambridge University Press, Cambridge, United Kingdom and New York, NY, USA, 996 pp.

Kalnay, E., and co-authors, 1996: The NCEP/NCAR 40year reanalysis project. Bull. Amer. Meteor. Soc., 77, 437-471.

Lambert, S. L., and J. C. Fyfe, 2006: Changes in winter cyclone frequencies and strengths simulated in enhanced greenhouse warming experiments: results from the models participating in the IPCC diagnostic exercise. Clim. Dyn., 26, 713-728.

Onogi, K., and co-authors, 2007: The JRS-25 Reanalysis. J. Meteor. Soc. Japan, 85, 369-432.

Räisänen, J., 2002: $\mathrm{CO}_{2}$-induced changes in interannual temperature and precipitation variability in 19 CMIP2 experiments. J. Climate, 15, 2395-2411.

Uppala, S. M., and co-authors, 2005: The ERA-40 reanalysis. Q. J. R. Meteor. Soc., 131, 2961-3012. 